\title{
EL MUNDO ACTUAL: VALORES Y CAMBIOS. LA PSICOLOGÍA Y SUS RESPUESTAS.
}

\author{
Noé de la Cruz Moreno \\ noe.valoresuniversales@gmail.com \\ Universidad Complutense de Madrid. Ministerio de Educación y Ciencia.
}

Fecha de Recepción: 1 Febrero 2018

Fecha de Admisión: 10 Abril 2018

\section{RESUMEN}

En el momento actual, estamos en un cambio de Ciclo Histórico, un mundo convulso y desorientado. Pérdida de valores, jamás imaginada, en la Familia, la Educación, relaciones humanas, religión, bases greco romanas, judeocristianas, sobre las que se ha edificado el desarrollo del mundo occidental. Los principios morales se esfuman en el viento. Los valores universales se incumplen con absoluta normalidad. El pasado está ligado al presente y al futuro, es el soporte ineludible de lo que va a venir. El pasado nos pasa factura. Los cambios de las últimas décadas han dejado a los países más desarrollados del mundo en estado de "shock". La defensa de la igualdad de derechos de la persona humana, mujer=varón, varón=mujer, negro=blanco, hétero u homo sexual ha marcado el camino irreversible en el mundo occidental; no, en el resto del mundo. Las Nuevas Tecnologías $e$ Internet "han lanzado en tropel la migración a la conquista del becerro de oro con patas de hojalata”. (De la Cruz N. 202). El divorcio exprés, la multiplicación de modelos de familia, el aborto indiscriminado, incluyendo a niñas y adolescentes, con pérdida alarmante de población, sustituida por los vientres de mujeres musulmanas, como pronosticó Muamar el Gadafi. El ciclo que empieza, durante el siglo XXI, pondrá nuevamente a la humanidad en el camino de avanzar de forma más equilibrada. Psicología, Pedagogía son el camino. Ámbitos de la vida familiar, escolar, social, políti$\mathrm{ca}$, se han judicializado hasta un nivel que sorprendería al mismo Franz Kafka. Las respuestas vienen necesariamente por dos vías: 1aㅡ, disminución, al mínimo, de abogados, jueces y de ginecólogos en el proceso de divorcios y abortos. 2ª . Atención humanizada y Educación Abierta Sistémica, incluyendo a todos, con las diferentes ramas de la Psicología, la Pedagogía y la Psicología Positivas, la Psicología y Pedagogía Prenatales.

Palabras clave: cambio; valores; respuestas; Educación Abierta; inclusión; psicología; pedagogía 


\section{EL MUNDO ACTUAL: VALORES Y CAMBIOS. LA PSICOLOGÍA Y SUS RESPUESTAS.}

\section{ABSTRACT}

\section{The current world: values and changes. psychology and its answers.}

At the present time, we are in a change of Historical Cycle, a convulsed and disoriented world. Loss of values, never imagined, in the Family, Education, human relations, religion, Greco-Roman, Judeo-Christian bases, on which the development of the Western world has been built. Moral principles vanish in the wind. The universal values are violated with absolute normality. The past is linked to the present and the future, it is the unavoidable support of what is to come. The past happens to us invoice. The changes of the last decades have left the most developed countries in the world in a state of "shock". The defense of the equal rights of the human person, woman = male, male = female, black = white, heterosexual or homo sexual has marked the irreversible path in the western world; no, in the rest of the world. The New Technologies and Internet "have launched in droves the migration to the conquest of the golden calf with tin legs". (De la Cruz N. 202). Express divorce, multiplication of family models, indiscriminate abortion, including girls and adolescents, with alarming Ioss of population, replaced by the bellies of Muslim women, as predicted by Muammar Gaddafi. The cycle that begins, during the $21^{\text {st }}$ century, will once again put humanity on the path to progress in a more balanced way. Psychology, Pedagogy are the way. Areas of family life, school, social, political, have been prosecuted to a level that would surprise the same Franz Kafka. The answers necessarily come in two ways: $1^{\text {st }}$, decrease, to a minimum, of lawyers, judges and gynecologists in the divorce and abortion process. $2^{\text {nd }}$. Humanized attention and Open Systemic Education, including everyone, with the different branches of Psychology.

Positive Pedagogy and Psychology, Prenatal Psychology and Pedagogy.

Keywords: change; values; answers; Open Education; inclusion; psychology; pedagogy

\section{INTRODUCCIÓN}

Vivimos en unos tiempos muy peculiares. Las relaciones humanas están pasando por unas contradicciones nunca vistas. El mundo se ha hecho muy pequeño y las normas de convivencia son contradictorias, aparecen y desaparecen según quien las dicta o quien las aplica. Efectivamente, como hemos señalado antes, formamos parte de un mundo convulso y desorientado. El mundo es un caos emocional, es un desorden intelectual que conduce necesariamente a un desorden social, material e incluso un desorden de principios éticos, un desorden moral. Necesita una psicoterapia colectiva, retomar el camino que conduzca a la tan deseada cordialidad y amor entre los seres humanos. No hay duda de que estamos en un cambio de ciclo histórico, iniciado con el nuevo Siglo. Hay quien me dice que soy exagerado y me adelanto a los acontecimientos. Sé que ha llegado a tocar fondo.

En principio, hacemos un breve análisis de contexto del mundo actual, destacando aquellos indicadores que nos dan una visión clara de la situación en la que nos encontramos. Destacamos en principio, los dos cambios muy positivos que se han dado durante el ciclo que termina. De un valor histórico inigualable, ha sido la consecución de la igualdad de derechos de todas las personas, ya sea blanco, negro, mulato, mestizo, mujer, varón o personas de diferente opción sexual. En esta lucha nos hemos implicado todos, viene de lejos y no ha sido fácil. A pesar de lo dicho, una parte considerable del mundo está todavía muy lejos de conseguirlo. Otros cambios inigualables en la calidad de vida, a través de los grandes descubrimientos en las nuevas Tecnologías de la Información y la Comunicación, son realidades de las que nos podemos sentir orgullosos.

No todo ha sido así. La guerra oculta, sorpresiva ejecutada por seres inhumanos, que dicen matar a sus semejantes en nombre de su Dios. Dos ejemplos, entre muchos, la guerra de Siria, años de muerte y desolación ante nuestros ojos. Dicen que hay una ONU, para qué sirve, quizá para rati- 
ficar los partes de guerra. La ironía de la ONU y de las grandes potencias es asegurar que no pueden intervenir en los asuntos de otros países. La osadía del poder, del dinero. Siento vergüenza, como ser humano, por la malévola justificación de acciones injustificables.

Hay otro hecho repugnante, enquistado ya, como un cáncer, en los corazones de piedra de los responsables de todos los países democráticos, el grupo criminal Boko Haram. Según ACNUR, Alto Comisionado de las Naciones Unidas para los Refugiados, en la última década, ha habido 25.000 asesinatos y más de 2.000 .000 huidos de sus hogares por las acciones de Boko Haram. Las migraciones descontroladas de África y de Oriente Medio están creando situaciones desconocidas e insuperables para los Países Europeos. Aumentan considerablemente el número de musulmanes, sumados a la elevada cantidad existente.

"Esta inmigración masiva acelera el auge del islam en varios países, creando guetos, zonas de exclusión, tribunales de la sharia, la poligamia, los matrimonios infantiles y la violencia por honor. La migración masiva también ha sido responsable del caos social, incluyendo ataques yihadistas, una epidemia de violaciones a manos de migrantes, una crisis de la salud pública, el aumento de la tasa delictiva".

https://es.gatestoneinstitute.org/10009/alemania-demografico-musulman

\section{LAS ENFERMEDADES SOCIALES DEL MUNDO ACTUAL.}

No vamos a hacer una relación exhaustiva, sería una lista excesivamente larga. Haremos mención y un breve análisis sólo de aquellas, que, por sí solas, tienen al mundo, especialmente al mundo occidental, "en ascuas". Son cánceres, algunos de ellos purulentos, con difícil pronóstico. Todos ellos son operables y superables. Para ser realistas, tenemos que asumir, que cada uno de ellos dejará secuelas difíciles de olvidar. Marcarán el principio del fin de un ciclo, el más corto de la Historia. Tenemos que aprender a digerir y a integrar todos los maravillosos descubrimientos en el ámbito de las Nuevas Tecnologías, del conocimiento del macrocosmos, del microcosmos, los límites de la inteligencia intelectual del ser humano. Evidentemente han mejorado nuestras vidas, nos han creado nuevos horizontes, porque la sociedad siempre va avanzando, a pesar de los pequeños parones, en cada cambio de ciclo. Todos estos adelantos han sido el producto de la inteligencia intelectual de unos cuantos seres humanos. Inteligencia que hemos heredado cada uno de nosotros.

La inteligencia emocional sí es creación nuestra a través de nuestro proceso de socialización, de nuestros hábitos y nuestro comportamiento. Es la orientación, la guía, las bridas del caballo desbocado de la inteligencia intelectual. Amparo Pastor Bustamante consideraba que la Inteligencia emocional nos permite tomar las riendas de nuestros propios impulsos, comprender y empatizar con los sentimientos y las emociones de los demás. Es más decisiva en el ámbito social que el cociente intelectual. Nuestro tiempo se distingue por el bajo nivel de Inteligencia emocional. En este nuevo ciclo histórico que empezamos, se ha trastocado, no sólo el orden, sino la propia existencia de los valores.

A Dios se le sustituye fácilmente por la Inteligencia del hombre, considerada ilimitada. La herencia Greco Romana y Judeo Cristiana, motor del desarrollo y bienestar del mundo libre, durante siglos, ha sido sustituida por el neo Marxismo, Socialismo Real, el nuevo Comunismo. Es decir, por la nueva izquierda, como aseguran Agustín Laje y Nicolás Márquez en su obra: "El libro NEGRO de la nueva IZQUIERDA". Utilizan estrategias fascistas, mientras hablan de Democracia, de Derechos Humanos (Ios suyos). El Comunismo fracasó, ahora utilizan nuevas estrategias, aparentes buenas formas, para hacer ver que la Nueva Izquierda viene para quedarse. No son la mayoría, pero están en todas partes, como mosquitos junto a los ríos en los días de calor del verano. Además... pican. Ideología que se ha ido filtrando muy suavemente desde los años setenta del siglo pasado, espe- 


\section{EL MUNDO ACTUAL: VALORES Y CAMBIOS. LA PSICOLOGÍA Y SUS RESPUESTAS.}

cialmente, desde la caída de la URSS y la unificación de Alemania. Ha conseguido debilitar a las Democracias occidentales, con políticos excesivamente tolerantes, mirando para otro lado, mientras se iba diluyendo en la población el elixir de su propia destrucción. El desorden social y la debilitación de las Democracias han traído otros males difíciles de erradicar. La generalización de las drogas, triplicando el consumo de heroína en los últimos diez años, la inseguridad ciudadana, la violencia doméstica generan un clima de intoxicación emocional sin encontrar fácilmente la salida.

Contagiado el virus en todo occidente, se ha apoderado de las relaciones humanas y sociales de nuestro tiempo. Un conocido Psiquiatra español, manifiesta, que, en el momento actual hay grandes epidemias en la humanidad, el desamor en las rupturas conyugales y el aborto son dos esenciales. Añado una más, la inmigración descontrolada, sin horizonte, sin porvenir, despoblando las tierras de origen, con un agravante añadido, los que emigran son los jóvenes mejor formados. La esperanza de desarrollo en esos países es nula.

\section{HABLEMOS DE LOS VALORES Y LOS CAMBIOS CON LAS GRANDES EPIDEMIAS SOCIALES: LAS RUPTURAS CONYUGALES, EL DIVORCIO.}

Ya no se aman, el desamor. Amor es la palabra mágica, más maravillosa en todos los idiomas. Las connotaciones inmediatas tienen que ver con el afecto, el cariño, la relación de empatía, sentimiento de apego a los demás, a las cosas, sensación de satisfacción con alguien o con algo, amor de pareja, a la familia, a los hijos, a los amigos. Amor es la palabra más polisémica que podamos encontrar. En el mundo de hoy hay una concepción errónea del amor, que justifica el desamor y la ruptura. Al sexo le llaman amor. El sexo tiene también un ingrediente del amor, que es el querer estar con otra persona, pero no siempre es amor, puede ser sólo deseo carnal puntual. El amor es mucho más que eso. El amor es entrega desinteresada, sin esperar nada a cambio. Es aceptar la diferencia en el pensar, en el sentir, en el obrar, en la discrepancia sin enfrentamiento, en la tolerancia. Incluyo aquí unos versos de un poema de Valores Universales: Escuchar-ceder-querer, esperar y respetar, eso sí es tolerar. El que escucha, El que cede, El que quiere y respeta; El que espera, ese, sí tolera. (De la Cruz, N.). El amor está en las pequeñas cosas de cada día. Efectivamente el divorcio es una plaga difícil de combatir, porque se ha introducido en nuestras vidas, como un hecho lo más natural de cada día. En España hay un divorcio cada cinco minutos. El divorcio exprés ante Notario es todavía mucho más destructivo.

El matrimonio es la estructura básica de la familia y ésta es la célula que forma las sociedades equilibradas. Durante el proceso de socialización familiar asume no sólo la identidad personal, sino los hábitos que conformarán su manera de conocerse a sí mismo y relacionarse adecuadamente con Ios demás. El divorcio corta ese proceso y deja a la prole desprovista de los valores, que asegurarán su equilibrio y el desarrollo de su Inteligencia Emocional. Cada año hay en España alrededor de 150.000 niños afectados por las consecuencias de la separación de sus padres. Es evidente que no es posible reducir a cero las separaciones conyugales, pero no lo es menos, que la realidad que tenemos cada día, como consecuencia de esas separaciones, nos exigen, especialmente a nosotros, estudiar el fenómeno desde distintas perspectivas y conseguir rebajar al mínimo posible los casos y minimizar los efectos en los hijos. Sin familia cohesionada el futuro es más difícil. Los modelos de familia se han multiplicado, en las últimas décadas, hasta los veintiséis modelos existentes.

El presidente de la Federación Europea "One Of Us", Jaime Mayor Oreja, ha declarado a través de un comunicado que "una sociedad que no protege la maternidad como esencia misma de la existencia de esa sociedad está abocada al caos".

El virus que afecta al matrimonio y a la familia es uno de los agentes que corroen, debilitan y destruyen al mundo en que vivimos. El efecto inmediato es la reducción drástica de la natalidad, 
hasta extremos preocupantes. El índice de fertilidad para mantener la población es de 2 ó 2,1 nacimientos por mujer. La realidad es deprimente: Actualmente, en Francia la tasa de fertilidad alcanza el 1,8 hijos por familia, seguida de Reino Unido, con 1,6 hijos por familia, en Alemania, Italia y Grecia 1,3, en España 1,1(en el 2012 era de 1,4). La tasa de Francia y del Reino Unido, se debe a la natalidad de la comunidad Musulmana, que alcanza el 8,1.

Nacimientos en España 1981, 677.456; en el año 2016, 408.384. (INE). En el 2017, el número de nacimientos fue un 6,3\% menor al del año anterior, 382.656. Fallecimientos en 2017: 414.788, es decir, 32.132 más que nacimientos.

Cuca Gamarra Alcaldesa de Logroño: "Afrontar ya el reto demográfico. Mañana será tarde".

"El Consejo de Ministros aprobó el 27 de enero de 2017 un Real Decreto por el que se crea el Comisionado del Gobierno frente al Reto Demográfico, regulando su funcionamiento. Se ha pronosticado una pérdida de más de medio millón de habitantes en 2031 y más de cinco millones de habitantes en 2066.

\section{EL ABORTO, LA GRAN EPIDEMIA DE LA SOCIEDAD.}

Es difícil encubrir con mayor osadía, con palabras dulces, una maldad de tales dimensiones. El nombre de una Ley describe el contenido que va desarrollar. En el caso del aborto no es así. No es posible encontrar en la Ley algún elemento en el que se encuentre algo que tenga que ver con la primera parte de su definición. Voy a relacionar algunas definiciones, que he podido recabar. Algunas de ellas muy duras, pero que sí describen la acción que se realiza en el aborto:

Asesinato y extracción de un "no nacido" del vientre de su madre.

Infanticidio y extracción de un "no nacido" del vientre de su madre.

Aborto programado e inducido.

Hay otra definición mucho más clara, según sus defensores: “Infanticidio con premeditación, con alevosía y sin defensión".

Cualquiera de las cuatro definiciones se entienden perfectamente. La primera parte del Título de la Ley no tiene nada que ver con el contenido de la misma, la segunda parte aclara suavemente la intención: Ley de salud sexual y reproductiva y de la interrupción voluntaria del embarazo.

"Salud sexual": Nadie dudaría de que se refiere a la manera más adecuada de vivir y practicar las relaciones sexuales, más sanas y más placenteras. "Salud reproductiva": Está orientada a una perfecta, consciente, planificada y deseada relación sexual, con el fin de concebir un nuevo ser. Es el ideal para planificar el inicio de la familia con su primer hijo o con hijos sucesivos, si así lo desean. En ninguno de los dos casos hay la más mínima semejanza con la segunda parte de la Ley, más bien es absolutamente lo contrario.

Algunos datos significativos. El Instituto Nacional de Estadística informa que hay unos

35.000 fallecimientos más que nacimientos en España. La cifra de abortos oficiales es alrededor de los 100.000 anuales. "Los abortos extraoficiales de acuerdo con una televisión danesa, pueden duplicar esta cifra. Filmó, con cámara oculta, en una clínica barcelonesa, y demostró que el aborto en España es libre hasta el mes nueve, con tal de que se paguen 4.000 euros. España se ha convertido en un gran coladero, en el paraíso del aborto europeo". Es decir, en España se superan los 200.000 abortos. Cubrirían sobradamente el déficit de nacimientos, superado por 32.132 fallecimientos.

Dinamarca deja en evidencia el fraude del aborto en España:

http://www.hispanidad.com/noticia.aspx?ID=14313

Las contradicciones de la Sociedad actual rota y esquizofrénica, la demografía se desangra. ¿Cuándo tendrá tiempo el Tribunal Constitucional de declarar anticonstitucional la Ley del aborto 


\section{EL MUNDO ACTUAL: VALORES Y CAMBIOS. LA PSICOLOGÍA Y SUS RESPUESTAS.}

de 2010?. "Podría señalar igualmente en qué casos podría estar justificado el aborto inducido, después de haber analizado las circunstancias en las que se dio la concepción. Por ejemplo, el caso reciente de una niña de 11 años violada. Cuando se tenga la evidencia científica de que esa vida no es viable o que está en grave peligro la vida de la madre”. (Noé de la Cruz, 2017).

Sólo en USA, desde que se legalizó el aborto, a principio de la década de los años setenta, ha habido más de 50.000 .000 millones de abortos. En Europa se realizan más de de abortos anuales, según cifras oficiales y 1.500 .000 , sumando los no controlados oficialmente.

La contradicción de estas cifras con las manifestaciones de algunos políticos relevantes de la Unión Europea:

En España hay cada año 35.000 fallecimientos más que nacimientos vivos. Al mismo tiempo, hay alrededor de 150.000 nacimientos muertos anuales (Io llaman abortos inducidos). En unos años, según los cálculos oficiales habrá bajado la población en 5.000 .000 de habitantes, que serán sustituidos con inmigrantes africanos y asiáticos, la mayor parte, musulmanes.

Alemania, según revela el Gobierno Alemán, necesitará, en las próximas tres o cuatro décadas, 40.000.000 millones de inmigrantes, de África, Asia y Oriente Medio, esencialmente musulmanes, para mantener la población y el bienestar actual. Lamentable y errónea pretensión. Francia y Gran Bretaña están también con unos niveles muy altos de inmigrantes no integrados, un elevado número de abortos y una disminución preocupante de población propia.

Estas migraciones del Siglo XXI, tienen características muy diferentes a todas las anteriores desde la Prehistoria. Son las que llamamos el gran movimiento de masas humanas migrantes hacia la tierra del bienestar, procedentes del cuarto mundo, el mundo pobre y sin desarrollo. El mundo, que en su día, ocupado por los países más desarrollados de Occidente, África y Oriente Medio, durante finales del Siglo XIX y Siglo XX, no fue colonizado para apoyar su desarrollo. Lo utilizaron durante décadas para extraer sus riquezas, sin repercutir en los propios aborígenes. Las nuevas tecnologías ponen ante sus ojos niveles de desarrollo inimaginables. Se lanzan para conseguir ese Edén, poniendo en peligro su propia vida. No emigran a Europa por placer sino por necesidad.

Rebajando los abortos hasta el mínimo terapéutico necesario, quedaría resuelto el problema y asegurado el bienestar. De esa forma sí se evitaría el cumplimiento de las profecías de Muamar el Gadafi y recientemente, del Señor Erdogán, asegurando, que en el año 2050, Europa será una República Islámica, gracias a los vientres de sus mujeres. Las francesas irán con el pañuelo y el hijah musulmán.

Otra contradicción no menos irónica que la anterior. "El aborto, además de aberrante es incongruente, en relación a la época en la que vivimos. Jamás, a través de la Historia de la Humanidad ha habido tanta facilidad, tantos medios eficaces, para tener sexo y prevenir los embarazos". (De la Cruz, N.). La irresponsabilidad, el egoísmo, la falta de educación y de respeto al otro, arrastran al ser humano a erotizar todos los momentos de la vida y a "animalizar" la conducta sexual.

\section{EL GRAN CAMBIO EN LAS RELACIONES HUMANAS. "LA IGUALDAD DE DERECHOS Y DEBERES"}

Sin duda es el cambio que ha transformado la Sociedad Occidental, felizmente, sin posibilidad de retorno, aunque, en el resto del mundo, falta mucho terreno por recorrer. Incluso, el mundo Musulmán se verá forzado por sus propias mujeres, a remover el muro intocable de siglos, por intereses machistas, haciendo a Dios responsable de sus comportamientos. Se ha consolidado el principio de que los derechos los tiene la persona, por el solo hecho de haber sido concebida. El derecho es de la persona, al margen del sexo, de la opción sexual, de la procedencia, del color de la piel 0 de los ojos, de la altura o de sus capacidades intelectuales. El ciclo anterior del Siglo XX y en las 
décadas del XXI, lo hemos conseguido. Muchos, mujeres y varones hemos trabajado sin tregua.. En el 1998, en el Plan Permanente de Educación en Valores Universales, escribí dos artículos, MUJER=VARÓN, VARÓN=MUJER, IGUALDAD DE DERECHOS, publicados en el año 2002 (De la Cruz, N.). Tuve además el honor de ser Concejal Delegado de Educación y del Área de la Mujer. Fue un trabajo intenso y muy gratificante, porque los resultados eran evidentes en todos los aspectos de la vida social y laboral.

\section{CÓMO AFRONTAR EL NUEVO CICLO: RESPUESTAS.}

Estamos viviendo los desequilibrios que han causado y siguen causando algunos de los cambios producidos en el último ciclo, hemos señalado algunas de las causas que los producen. La vida de cada día se ha judicializado y se ha tecnificado en cada paso que damos, la violencia generalizada, la multiplicación y diversificación de las drogas, la deshumanización, la pérdida de Valores Universales, nos han llevado al límite de que el espíritu y la moral no cuentan. La ideologización universal no duerme, está siempre en todos sitios. Hasta al género le ponen ideología, “ideología de género", aberrante. Lo excepcional marca el camino obligatorio a lo general. Los LGBT son los que mandan. Lo que se lleva es tener sexo a discreción (dicen hacer el amor), sin pensar en las consecuencias. Volvemos al Monte Taigeto de Esparta 0 a los crematorios de Hitler. Ahora, incluso se utilizan para cremas o para investigación. Lo dicho aquí es sólo la punta del Iceberg.

La vida personal, familiar, social, política, de vecindad, etc, etc, está judicializada. El divorcio, como hemos visto, está de moda. Para mayor rapidez se facilitó con el "divorcio exprés". El desamor lo arreglan de inmediato los Notarios, los abogados y los Jueces. Detrás quedan los hijos; que se encargue el Estado, la Escuela y si los hay todavía en condiciones, los abuelos. Yo me voy con uno, tú te vas con otra y "pelitos a la mar".

Lo mismo ocurre con el infanticidio, penalizado muy severamente si no hay una Ley que lo ampare; en ese caso se llama infanticidio legal, "interrupción voluntaria del embarazo", también denominado, aborto inducido, que no suena tan brusco. La mujer es libre para hacerlo, no tiene que contar con nadie, sin pensar que lo que lleva dentro es otra persona. La libertad la tenemos por ser personas, no por ser varón o mujer. Con nuestra propia vida podemos hacer lo que queramos, con la del otro, no. En este caso hay ginecólogos que hacen la faena de matar al non nato y extraerlo. Previamente, en teoría, hay orientadores, psicólogos, pagados por los abortorios.

El desorden y la utilización mafiosa de las migraciones desesperadas, "caminando hacia ninguna parte". En Europa no cave toda África, esa no es la solución.

Las respuestas están en revertir estas situaciones, humanizando nuevamente la vida diaria, para entrar en el nuevo ciclo, como si fuéramos personas con conciencia. Quién y cómo se puede hacer. Primero, tomar conciencia de la realidad y no negarla. Segundo, La Educación Abierta, incluyendo a todos, centrada en el aprendizaje y en las necesidades de las personas, sea cual sea su situación personal, familiar, social, laboral y sus necesidades específicas. Todo ello con el apoyo de las Ciencias afines, la Psicología en sus distintas Modalidades, la Pedagogía con sus diversas estrategias didácticas y de organización, la Biología y la Neonatología con su investigación prenatal. Tercero, aprobar Leyes que piensen en el bienestar de las personas, en buscar soluciones positivas, creativas, humanas. Cuarto, crear oficialmente equipos de escucha, ayuda y orientación, Trabajadores Sociales, Psicólogos, Psicopedagogos, especialmente en el aborto y en el divorcio. Los Profesionales de la Medicina y de la Judicatura, sólo participarían en los casos puntuales, previamente orientados. Asesoramiento psicológico, legal, económico y de acompañamiento.

Las migraciones inhumanas del cuarto mundo sólo se resuelven creando en sus países de origen, infraestructuras adecuadas, industria, vías de comunicación para un comercio fluido. 


\section{EL MUNDO ACTUAL: VALORES Y CAMBIOS. LA PSICOLOGÍA Y SUS RESPUESTAS.}

Paralelamente acometer un Plan General de Educación a través del Modelo de ProgramaciónEvaluación de la Educación Abierta. Estas actuaciones las deber emprender los Países Occidentales que asumieron un día la Colonización del Continente Africano y de Oriente Medio y no lo realizaron. Con los recursos que se están gastando infructuosamente con los inmigrantes desconcertados y desintegrados bien se puede realizar una obra humana y positiva con proyección de un futuro mejor para todos. Con el tiempo visitarán Europa como turistas y no como inmigrantes desesperados.

\section{BIBLIOGRAFÍA CONSULTADA}

Cirigliano, G. La Educación Abierta. Buenos Aires: El Ateneo.

De la Cruz, N. (2016). Otra manera de enseñar es posible. Madrid: La Muralla.

- (2017). La Educación Abierta y la Educación Familiar mirando al futuro.

Berlín: EAE (Member of OmniScriptum Publishing Group).

Márquez, N. Laje, A. (2016). El libro NEGRO de La nueva IZQUIERDA. Madrid: Unión Editorial.

Roubini, N. Mihm, S. Cómo salimos de ésta. (2010). Barcelona: Ediciones Destino. Sukup, Viktor.

(2016). El Caribe frente a los desafíos del futuro. Badajoz: CEXECI.

- www.valoresuniversales.es:

- http://www.valoresuniversales.es/educacion-abierta-siglo-xxi/

- http://www.valoresuniversales.es/igualdad-derechos/

- http://www.valoresuniversales.es/igualdad-derechos-ii/

- http://www.valoresuniversales.es/inmigracion-diversidad-cultural-educacion/

- http://www.valoresuniversales.es/carta-europea-valores/

http://www.valoresuniversales.es/modelo-escolar-sistema-abierto-flexible-saf/

http://studylib.es/doc/6001773/educaci\%C3\%B3n-prenatal-y-pedagog\%C3\%ADa- prenatal.

https://www.bebesymas.com/recien-nacido/el-mapa-de-la-maternidad-en- europahttp://www.hispanidad.com/noticia.aspx?ID=14313https://es.gatestoneinstitute.org/1 0009/alemania-demografico- musulmanhttps://www.google.es/search?q=Alemania+el+Rheinische+Post+musulmahttps://w ww.google.es/search?q=Alemania+comedores+católicos+necesita. 